\title{
Effects of alternating classical conditioning and extinction sessions on the conditioned nictitating membrane response of the rabbit
}

\author{
MARIUS SMITH AND I. GORMEZANO
}

INDIANA UNIVERSITY

\begin{abstract}
Eleven Ss received four acquisition sessions of classical conditioning training followed by 11 alternating sessions of conditioning and extinction. Although Ss demonstrated a relatively high degree of stability of responding over extinction sessions the form of the extinction function within sessions changed over sessions. The results were contrasted with analogous instrumental conditioning experiments.

\section{Results}

In several instrumental conditioning studies decreasing resistance to extinction following repeated alternating conditioning and extinction sessions has been observed in rats (Perkins \& Cacioppo, 1950; Bullock \& Smith, 1953), pigeons (Roberts, Bullock \& Bitterman, 1963), and fish (Gonzalez, Eskin \& Bitterman, 1962). Such changes in extinction are frequently attributed to a learned discrimination between conditioning and extinction session, established on the basis of the occurrence or nonoccurrence of the reinforcer on the preceding trial (s), (e.g. Bullock \& Smith, 1963). However, two studies employing classical aversive conditioning in the fish (Gonzalez, Longo \& Bitterman, 1961; Gonzalez, Milstein \& Bitterman, 1962) have failed to reveal marked changes in extinction performance over repeated conditioning and extinction sessions. The purpose of the present study was to determine whether or not the classically conditioned nictitating membrane response of the rabbit would reveal decreasing resistance to extinction following repeated conditioning and extinction sessions.
\end{abstract}

Method

The apparatus and preparation has been described (Schneiderman \& Gormezano, 1964). In the present study two flat stainless steel shock electrodes, coated with electrode paste, were applied to the skin immediately dorsal to the external lids. Eleven albino rabbits, 80-100 days old, were placed in restraining boxes while the hair around the orbital region of S's right eye was removed and a small nylon loop sutured into the nictitating membrane. On the following day Ss were adapted for $40 \mathrm{~min}$. to the experimental apparatus consisting of a sound-deadened enclosure, restraining stock and head gear. Following adaptation Ss received four days of acquisition training consisting of 80 pairings of a $700 \mathrm{msec}_{\text {., }} 1000 \mathrm{cps}$ tonal CS of $85 \mathrm{db}$ and a 200 msec., $60 \mathrm{cps}, 3.0 \mathrm{ma}$ shock UCS. The CS-UCS interval was $500 \mathrm{msec}$. and the two stimuli terminated

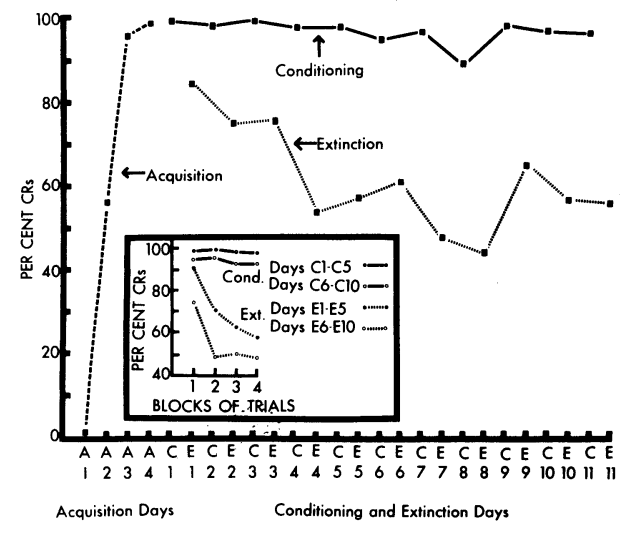

Fig. 1. The percentage $\mathrm{CRs}$ for acquisition, and alternating conditioning and extinction days. The small enclosed plot (insert) shows the mean percentage CRs in blocks of 20 trials within the first five and second five conditioning days and extinction days.

simultaneously. The intertrial intervals were 20,30 , and $40 \mathrm{sec}$. After the four days of acquisition training Ss received 11 days of conditioning alternating with 11 days of extinction. Both the conditioning and extinction sessions were identical to the original acquisition sessions with the exception that the UCS was omitted during extincition.

\section{Results and Discussion}

The large plot in Fig. 1 presents the percentage CRs in acquisition (Days A1-A4) and subsequent alternating days of conditioning (Days C1-C11) and extinction (Days E1-E11). A small decrement in conditioning and a larger decrement in extinction performance over days are revealed in the large plot and also in the insert by the lower level of performance on Days C6-C10 relative to Days C1-C5, and on Days E6-E10 relative to Days E1-E5. The insert reveals only slight changes over blocks of trials within conditioning days, but marked decrements over blocks of trials within extinction days. Further, the initial segment of the extinction curve for Days E6-E10 appears to be steeper than for Days E1E5.

Percentage CRs for blocks of 20 trials were treated by the arc-sine transformation. Analyses of variance revealed that the changes in performance over days were reliable for both conditioning Days C1-C11 (F, 2.33; $\mathrm{df}, 10 / 100 ; \mathrm{p}<.05)$ and for extinction Days E1-E11 ( $F, 3.18 ; d f, 10 / 100 ; p<.005)$. The Conditions effect 
(conditioning vs. extinction) was significant (F, 89.86; df, $1 / 10 ; p<.001)$; but the Days by Conditions interaction was not (F, 1.51; df, 10/100; p> .10). A significant change in extinction performance over Blocks of trials ( $F, 56.14 ; \mathrm{df}, 3 / 30 ; \mathrm{p}<.001$ ) and a significant Days by Blocks interaction in extinction (F, 1.74; df, $30 / 300 ; p<.05)$ indicated that reliable changes occurred within extinction days and that the form of the extinction function changed over days. For conditioning days neither the Blocks effect $(F, 2.40 ; d f, 3 / 30 ; p>.05)$ nor the Days by Blocks interaction ( F, 1.08; df, 30/300; $p>.20$ ) was significant. An analysis in which the Days variable was collapsed into days one through five and days six through ten (corresponding to the data presented in the insert) failed to reveal a significant Days by Blocks interaction for conditioning days (F, 0.27; df, $3 / 30 ; p>.50)$. However, a significant Days by Blocks interaction was obtained for extinction days (F, 3.20; df, $3 / 30 ; p<.05$ ) indicating further, that reliable changes occurred in the form of the within session extinction function over days.

The observed decline in performance over extinction days and the increased initial steepness of the extinction function on later extinctions (i.e. the Days by Blocks interaction) are in accord with the discrimination hypothesis. However, in contrast with the striking changes observed in analogous instrumental conditioning situations (cf. Bullock \& Smith, 1953), the extinction performance in the present study showed a remarkable degree of stability over repeated extinction sessions. Further, it is possible that the observed changes in extinction performance over sessions might have resulted from the slightly decreasing level of performance over conditioning days. The failure of the Days by Conditions interaction to reach significance would be compatible with such an interpretation. Nevertheless, the results lend tentative support to the hypothesis that a discrimination between classical conditioning and extinction sessions can be established on the basis of the occurrence of the UCS on the preceding trial (s).

\section{Referenees}

Bullock, D. H., \& Smith, w. C. An effect of repeated conditioning extinction upon operant strength. J. exp. Psychol., 1953, 46, 349-352.

Gonzalez, R. C., Eskin, Rochelle M., \& Bitterman, M. E. Extinction in the fish after partial and consistent reinforcement with number of reinforcements equated. J. comp. physiol. Psychol., 1962, 55, 381-386.

Gonzalez, R. C., Longo, N., \& Bitterman, M. E. Classical conditioning in the fish: exploratory studies of partial reinforcement. J. comp. physiol. Psychol., 1961, 54, 452-456.

Gonzalez, R. C., Milstein, Sandra, \& Bitterman, M. E. Classical conditioning in the fish: further studies of partial reinforcement. Amer. J. Psychol., 1962, 75, 421-428.

Perkins, C. C., \& Cacioppo, A. J. The effect of intermittent reinforcement on the change in extinction rate following successive reconditionings. J. exp. Psychol., 1950, 40, 794-801.

Roberts, W. A., Bullock, D. H., \& Bitterman, M. E. Resistance to extinction in the pigeon after partially reinforced instrumental training under discrete-trials conditions. Amer. J. Psychol., 1963, 76, 353-365.

Schneiderman, N., \& Gormezano, I. Conditioning of the nictitating membrane of the rabbit as a function of CS-US interval. J. comp. physiol. Psychol., 1964, 57, 188-195.

\section{Note}

1. This research was supported by Grant GB-2843 from the National Science Foundation.

\section{Comment}

Rosen \& Ison (1965) rewarded three groups of rats with 400 licks of $20 \%$ sucrose, 400 of $3 \%$, or 20 of $3 \%$, then shifted all groups to the latter reward during the second stage of the experiment. In accounting for differences in running speed during the second stage, the authors examine two possible sources of variance: experimental treatment during the first stage, and lick rate observed during the second stage. They conclude that "... the correlations between licking rate and running speed, though of the moderate magnitude characteristic of these situations, do not account for a great percentage of the variance between Ss."

The correlations reported clearly support this conclusion, but it seems fair to ask how great a percentage is accountable to the experimental treatments given during Stage 1. The authors present no indices comparable to $r^{2}$, such as $\omega^{2}$ (Hays, 1963), and from the data reported the interested reader can not calculate such indices for himself. There is one exception. Considering response speeds on the last day of the second stage, the authors report a t-test comparing the two extreme treatment groups, $400-20 \%$ and $20-3 \%$. The $t$ value reported shows that treatment is responsible for

about $19 \%$ of the variance. It is difficult to compare this figure with variance accountable to lick rate, for two reasons. First, the correlation between lick rate and running speed on the last day is not reported. They do report a correlation based on all Ss, between lick rate and running speed during the whole of Stage 2, indicating that lick rate accounts for about $10 \%$ of the variance. Second, variance accountable to two extreme experimental treatments may not be strictly comparable to $\mathbf{r}^{2}$ based upon all Ss. If we selected Ss with extremely high, and Ss with extremely low lick rates, $r^{\hat{2}}$ based on these extreme groups could conceivably exceed .10 or even .19.

The predictive value of lick rate may indeed be moderate, but it is hard to tell from the data reported whether experimental treatment is better or worse in this regard.

\section{References}

Hays, W. L. Statistics for psychologists. New York: Holt, Rinehart, and Winston, 1963

Rosen, A. J., \& Ison, J. R. Runway performance following changes in sucrose rewards. Psychon. Sci., 1965, 2, 335-336.

James Allison Indiana University

(For reply by Ison and Rosen, see page 100) 